\title{
REPENSANDO LA ACEPTABILIDAD Y ADAPTABILIDAD DE LA DOCENCIA VIRTUAL UNIVERSITARIA.
}

\author{
RETHINKING THE ACCEPTABILITY AND ADAPTABILITY OF VIRTUAL \\ UNIVERSITY TEACHING.
}

\author{
Johanna Vargas Ugalde \\ Dra.(c) en Educación \\ Universidad Central \\ johannavargasug2@gmaill.com \\ Isabel González Ramírez \\ Dra. en Derecho \\ Universidad Central \\ igonzalezr@ucentral.cl
}

\begin{abstract}
Resumen: Este artículo se propone develar los nudos críticos de las políticas educativas vigentes asociadas a la calidad de la docencia universitaria virtual en Chile durante la pandemia por Covid, para lo cual se realizó un estudio cualitativo exploratorio-descriptivo, sustentado en el análisis crítico del discurso y cuyo corpus fueron los documentos orientadores publicados por las agencias estatales durante dicho período. La revisión documental permitió indagar en tres dimensiones de la calidad de la docencia virtual: contenidos, metodología de trabajo docente y sólida formación del profesorado (Martelo, Franco y Oyola, 2020). Se concluye que el rol subsidiario del Estado ha propiciado la generación de políticas públicas educativas laxas las que, apelando a la autonomía institucional, reproducen desigualdades y asimetrías socioeducativas, replicando estructuras formativas hegemónicas, lo cual afecta de manera más profunda el aprendizaje de los estudiantes provenientes de familias con bajo capital sociocultural y que suelen acudir a planteles de menor selectividad, sin existir medidas desde el nivel central que efectivamente aseguren la calidad de la docencia virtualizada y que esté erigida sobre la pertinencia de contenidos, metodologías de trabajo apropiadas y sólida formación del personal académico.
\end{abstract}

Palabras Claves: educación superior, calidad educativa, docencia virtual, aceptabilidad y adaptabilidad, políticas públicas educativas.

Abstract: This article aims to unveil the critical knots of current educational policies associated with the quality of virtual university teaching in Chile during the Covid pandemic, for which an exploratory-descriptive qualitative study was conducted, based on the critical analysis of discourse and whose corpus were the guiding documents published by state agencies during that period. The documentary review made it possible to

Fecha recepción: 13 de abril de 2021

Fecha aceptación: 10 de junio de 2021 
investigate three dimensions of the quality of virtual teaching: content, teaching methodology, and solid teacher training (Martelo, Franco, and Oyola, 2020). It is concluded that the subsidiary role of the state has led to the generation of lax public educational policies which, appealing to institutional autonomy, reproduce inequalities and socioeducational asymmetries, replicating hegemonic training structures, This has a more profound effect on the learning of students from families with low socio-cultural capital and who tend to attend less selective schools, without measures from the central level that effectively ensure the quality of virtualized teaching and that is built on the relevance of content, appropriate working methodologies and solid training of academic staff.

Key Words: higher education, educational quality, virtual teaching, acceptability and adaptability, educational public policies.

Resumo: Este artigo tem como objetivo desvelar os nós críticos das políticas educacionais atuais associadas à qualidade do ensino universitário virtual no Chile durante a pandemia de Covid, para a qual foi realizado um estudo exploratório-descritivo qualitativo, apoiado na análise crítica do discurso e cujo corpus foi os documentos norteadores publicados por órgãos estaduais naquele período. A revisão documental possibilitou investigar a qualidade do ensino virtual em três dimensões: conteúdo, metodologia de ensino e sólida formação docente (Martelo, Franco e Oyola, 2020). Conclui-se que o papel subsidiário do Estado tem levado à geração de políticas públicas educacionais frouxas que, apelando para a autonomia institucional, reproduzem desigualdades e assimetrias socioeducativas, replicando estruturas hegemônicas de formação, o que afeta de forma mais profunda a aprendizagem. dos alunos oriundos de famílias com baixo capital sociocultural e que tendem a frequentar as escolas com menor seletividade, sem medidas de nível central que efetivamente garantam a qualidade do ensino virtualizado e que se construa na relevância dos conteúdos, nas metodologias de trabalho adequadas e sólida formação do corpo docente.

Palavras chave: ensino superior, qualidade educacional, ensino virtual, aceitabilidade e adaptabilidade, políticas públicas educacionais.

\section{INTRODUCCIÓN}

En tiempos de pandemia, la educación superior ha debido repensarse, no solamente desde la inherente responsabilidad formativa, sino más bien como un campo que evidencia inequidades, hegemonías, cierres y aperturas. Por lo mismo, la aceptabilidad y adaptabilidad de la docencia virtual en el contexto universitario chileno se constituye en problema social debido a la configuración binaria de instituciones de educación superior, coexistiendo entidades de elite y otras destinadas a la masa (Zapata y Tejeda, 2017), con disímiles modelos educativos, currículos y calidad del cuerpo académico, entre otros aspectos.

La proliferación de entidades de diversa calidad también ha sido una consecuencia de las políticas públicas orientadas al subsidio de la demanda, las que, amparadas en el principio constitucional de subsidiariedad estatal, han generado la mercantilización del derecho a la 
educación, lo cual ha implicado que muchos grupos de poder generen empresas que directa o indirectamente se vinculan con la educación. Por lo anterior, es que el sistema educacional también, para algunos, opera como una línea de negocio rentable, pudiendo generar una multiplicidad de productos y servicios asociados, como, por ejemplo, las mediciones estandarizadas, lo cual ha sido evidenciado en estudios precedentes (Verger y Normand, 2015; Verger y Parceriza, 2017). Así, actualmente las plataformas virtuales también se han transformado en un auspicioso escenario para dichos empresarios.

Al detentar el sistema educativo una estructura piramidal (Guzmán, 2016), las posibilidades de ingresar aumentan, pero las diferencias entre tipos de estudiantes se hacen más evidentes, especialmente cuando las clases deben ser realizadas a través de plataformas informáticas, puesto que, la existencia de dichos soportes no tiene un correlato con lo pedagógico. Es decir, las tic's no necesariamente pueden asegurar la calidad, pertinencia y adaptabilidad curricular.

Algunos investigadores (García Plana y Taberna Torres, 2020) señalan que el principal inconveniente de la docencia virtual es la inexistencia de un marco teórico que permita la organización del proceso de enseñanza. Sin embargo, y aunque es necesario contar con un soporte teórico que permita la comprensión del fenómeno, el presente estudio propone que la calidad de la docencia virtual no puede estar supeditada de manera exclusiva a la dimensión tecnológica y/o informática educativa, la cual suele asociar la docencia virtual con la existencia de plataformas o en el dominio de las tic's por parte del cuerpo académico, directivos y profesorado, entre otros aspectos. Por el contrario, la idea fuerza que sustenta a esta investigación remite a la concepción de la calidad educativa como un derecho, el cual se erige a partir de dos principios inherentes al quehacer pedagógico, como son la aceptabilidad y la adaptabilidad, es decir, que la calidad del currículo desplegado frente a los estudiantes sea acorde a las necesidades formativas de ellos y que el modelo pedagógico y curricular esté diseñado y adaptado a las características de dichos estudiantes.

Según lo anterior, este artículo da cuenta de una investigación cualitativa, sustentada en el análisis crítico del discurso (van Dijk, 2016) y cuyo objetivo fue develar los nudos críticos de las políticas educativas vigentes asociadas a la calidad de la docencia universitaria virtual en Chile durante la pandemia por Covid, país que, al igual que todo el planeta, ha debido llevar las aulas físicas a plataformas informáticas. Sin embargo, la virtualización es un fenómeno que en dicha nación se produjo antes de la pandemia, debido a la crisis social que paralizó diversas zonas del país desde octubre de 2019. Según esto, la pregunta que guía este análisis alude a: ¿Cuáles son los elementos ideológicos presentes en el discurso oficial alusivo a la docencia universitaria virtual durante la pandemia? De igual modo, este planteamiento propone que es plausible que existan diferencias sustanciales en la calidad de la docencia virtual según tipos de planteles, estableciéndose la siguiente hipótesis: ante las directrices de agencias estatales durante la pandemia por Covid, la política pública ha invisibilizado a la calidad de la docencia como un componente relevante de la dimensión curricular. Por lo mismo, dicha calidad no estará representada, operacionalizada o definida en ningún dispositivo (Luna, 2020; Foucault, 2006), por ende, la aceptabilidad y adaptabilidad de los procesos formativos durante la pandemia no están garantizadas, afectando con ello derechos fundamentales de los estudiantes. 
Concretamente, para conocer los nudos y elementos ideológicos que están presentes y entrampan a la docencia virtual universitaria durante la pandemia, se efectuó una revisión que, primeramente, permite aproximarse al constructo "docencia virtual", es decir, aquella efectuada a través de plataformas online, la cual, al igual que los métodos tradicionales o presenciales, se encuentra performada por los discursos oficiales.

En segundo lugar, se explicitan los discursos políticos oficiales, es decir, las medidas y/o acciones tomadas por las agencias estatales para resguardar, tanto la calidad de la educación superior en general, como la pertinencia y adaptabilidad de la docencia online durante la pandemia, así como también la alineación de aquello con las disposiciones del Pacto Internacional de Derechos Sociales y Económicos (PIDESC).

El tercer apartado detalla el método, por lo cual se alude al estudio cualitativo de las políticas públicas educativas desde una perspectiva crítica discursiva (Van Dijk, 2016; 2017), considerando para esto las orientaciones emanadas desde las agencias estatales, así como también el marco normativo alusivo a la calidad de la docencia en educación superior y que regulan el accionar de los órganos del Estado encargados de supervisar a las universidades, siendo ello analizado en función de tres categorías alusivas a la docencia virtual, como son: la calidad de contenidos; la metodología de trabajo docente y la sólida formación del profesorado (Martelo, Franco y Oyola, 2020). Dicho análisis se realizó tomando como referentes la aceptabilidad y adaptabilidad de la enseñanza virtual en pandemia, lo cual se asocia a los derechos sociales resguardados por los pactos y convenciones internacionales de DDHH ratificados por el Estado de Chile y que tienen el estatus de ley de la República.

Posteriormente, se presentan los resultados, mostrando cómo los referentes de la calidad educativa, provenientes del discurso oficial, promueven desigualdades sociales. Expresado de otra manera, se evidencia la existencia de acoplamientos de los textos oficiales con los intereses de los grupos dominantes (como pudiesen ser los miembros del sistema político, institucional o académico, entre otros), dando cuenta de cómo esta relación no se ocupa de las necesidades de los grupos de menor estatus dentro de la sociedad, como son los estudiantes universitarios vulnerables, con especial atención a aquellos que cursan carreras en planteles de baja selectividad que reciben a ingresantes provenientes de los quintiles de menor ingreso y cuyas familias detentan un capital sociocultural más débil.

Finalmente, se exponen las conclusiones, las que en línea con Verger y Normand (2015); y Verger y Parceriza (2017) muestran cómo las políticas públicas operan como dispositivos que no buscan el cambio o mejoramiento educativo. Más aún, no se espera que ellas funcionen, puesto que, al estar alineadas con macroproyectos hegemónicos $y$ colonizadas por lenguajes tecnocráticos y mercantilistas, entonces la calidad del currículo se invisibiliza y la docencia virtual, como medio para la consecución de la calidad educativa y vía para la superación de la inequidad social, no se asume como relevante, por lo tanto, dicha (mala) calidad termina perpetuando asimetrías y desigualdades sociales, cristalizando aquello en los estudiantes y su desarrollo profesional. 


\section{ANTECEDENTES TEÓRICOS}

\section{Docencia virtual y sus implicancias}

El contexto sociohistórico en el cual se produce la pandemia en Chile está cruzado por diversas complejidades que emergen a la luz del estallido social de octubre de 2019, el cual también se vincula con las demandas ciudadanas asociadas a la educación de calidad y gratuita -o a un costo que permita a los estudiantes de grado o posgrado no endeudarse de por vida-. Expresado de otra forma, tanto dicho estallido, como la pandemia, dan vida a un proceso histórico y político, el cual construye y redefine el quehacer pedagógico en el aula.

Dicho momento histórico provocó que los estudiantes cursen sus materias a través de plataformas online, modalidad educativa que posee ciertas particularidades, implicando nuevos roles docentes, lo cual va más allá del uso de tecnologías educativas, puesto que implica la incorporación de metodologías apropiadas y profesores capacitados para esta nueva forma de trabajo. Es decir, ha llegado el momento en que los modelos pedagógicos utilizados por los docentes en entornos universitarios virtuales den cuenta de su real aporte a la sociedad, siendo para ello clave el rol de la política pública en tanto garante de los derechos de miles de universitarios.

El Estado de Chile en tiempos de pandemia generó documentos orientadores, los que alineados al plan de fiscalización desarrollado por la Superintendencia de Educación Superior (SES), consideran la ejecución de acciones específicas por parte de las instituciones de educación superior (IES), cuyos ejes son: gestión curricular, docencia y acompañamiento estudiantil. Dicho de otra forma, desde el aparato estatal se propusieron acciones o lineamientos para el desarrollo de la enseñanza universitaria virtual, lo cual se constituye en un escenario no exento de críticas, especialmente porque la contingencia ha propiciado la delegación de algunas tareas pedagógicas desde las universidades a entidades externas y cuya misión ha consistido en brindar soporte informático, el cual transita por un confuso horizonte tecnológico-pedagógico.

La docencia virtual está estrechamente vinculada a la dimensión curricular, es decir, qué y cómo se enseña, siendo esto definiciones educativas relevantes. Así, antes de la pandemia, el currículo en educación superior (ES) ha estado en tensión, puesto que, al ser una síntesis de elementos culturales explicita las intenciones y modos de la política educativa, la cual define el cúmulo de relaciones y estructuras de la sociedad (Morelli, 2017; De Alba, 2012), por ende, remite a lo hegemónico, puesto que se alinea a los proyectos políticos de quienes lo impulsan, dentro de un macrocosmos que va más allá de la política partidaria y que lo inserta en un complejo entramado sociohistórico.

Según lo anterior, el poder siempre emerge desde el discurso curricular, puesto que es una fuerza constitutiva de lo que acontece en el aula (virtual) y/o espacio de interacción en el cual la propuesta curricular adquiere voz. Por lo mismo, el discurso usado por las agencias estatales durante la pandemia también pudiese obedecer a un modo de colonización discursiva, puesto que, en los textos se pueden observar los tipos de líneas argumentativas existentes. Así, por ejemplo, durante las últimas décadas ha primado el lenguaje económico por sobre lo pedagógico, lo cual ha posicionado al accountability e invisibilizando a la dimensión curricular. 
Las tendencias hegemónicas del sistema de enseñanza se plasman en acciones específicas. Por lo mismo, los diseños de aulas virtuales también son un campo y representación del poder de ciertos actores o grupos sociales que han establecido $\mathrm{y}$ perpetuado una estructura educativa piramidal, lo cual implica una estratificación de la educación superior (Guzmán, 2016). Así, mientras las posibilidades de ingreso a la ES se incrementan, las asimetrías se hacen más evidentes entre planteles y estudiantes. Es decir, la construcción binaria de entidades destinadas a alumnos de élite y otras dirigidas a la masa (Zapata y Tejeda, 2017), hacen que la calidad de la docencia, en especial de la virtual, también esté afecta a brechas insoslayables.

La docencia virtual implica modos distintos de construir la relación con el estudiantado, el diseño de materiales específicos y acordes, acciones tutoriales y la regulación de procesos asincrónicos se presentan como relevantes para esta alternativa educacional, lo cual supone un desafío para las entidades educacionales, así como también docentes con perfiles distintos a los tradicionales (Barberá y Badía, 2005) y que obligan al profesor a asumir una nueva realidad, en la cual la tecnología tiene un rol de vital importancia (Torrecillas, 2020) y cuya evaluación se torna compleja. Sin embargo, la existencia de soportes informáticos no asegura la calidad de la enseñanza, puesto que, aunque la relación con el estudiante es remota, las competencias, saberes y dominios disciplinares y pedagógicos del profesor siguen siendo preponderantes.

Una debilidad para la implementación y evaluación de la docencia virtual es la inexistencia de un marco teórico que permita la organización de la enseñanza (García Plana y Taberna Torres, 2020). Así, gestores y profesores, probablemente sin formación específica para el desarrollo de procesos pedagógico-curriculares virtuales, tuvieron que adoptar en pandemia un nuevo paradigma formativo, puesto que, cada actividad es en sí misma una evaluación del rendimiento o avance individual. Ello requiere de constante retroalimentación, lo cual es complejo, pudiendo acontecer que los administradores de los planteles y aulas virtuales decidan incorporar una cantidad excesiva de estudiantes, imposibilitando dicha retroalimentación. De igual forma, también se ha pesquisado como problema el exceso de contenidos, puesto que las plataformas poseen una capacidad que permite sobrepasarse (García Plana y Taberna Torres, 2020) o, lo que es peor, son administradas por personas que no conocen el currículo específico de cada carrera, por ende, piden cierto tipo y cantidad de materiales pedagógicos a los docentes que, en muchos casos, no tienen justificación o anclaje teórico- práctico con la asignatura. Dicho de otro modo, frente a este nuevo escenario virtual, surge la tensión entre la dimensión tecnológica de la enseñanza y el dominio pedagógico-curricular y disciplinar del profesor.

Por otra parte, la evaluación de la calidad de la docencia virtual es un campo muy poco explorado. Al respecto, Marciniak y Sallán (2018) precisan que en la actualidad no existe un único modelo que permita medirla. Así, tras analizar cuantitativamente 25 modelos, dichos investigadores encontraron concordancias que aluden al factor docente y aspectos pedagógicos. Es decir, sus hallazgos demuestran que el perfil del profesor online y su desarrollo profesional, así como los objetivos formativos, recursos didácticos, procesos de evaluación del aprendizaje y estrategias de enseñanza son dimensiones que consistentemente dan cuenta de la calidad de la docencia virtual. 
En otro estudio de similar metodología, Martelo, Franco y Oyola (2020) evidenciaron que, de 17 factores sugeridos por la literatura académica respecto a formación online de calidad, los más relevantes o estratégicos resultaron ser los siguientes: Autogestión de los contenidos de aprendizaje; Atemporalidad didáctica y cumplimiento de tareas; Calidad de contenidos; Metodología de trabajo; Empatía con el entorno; Flexibilidad del curso; Sólida formación del profesorado; y Seguimientos estudiantes, siendo el tercero, cuarto y séptimo aquellos que tienen estricta relación con la docencia. Dicho de otra manera, la calidad y estructuración de los temas de clases, la organización del trabajo académico y el dominio pedagógico del profesor resultaron como relevantes para la calidad de la educación superior virtual.

En pandemia resulta complejo erigir un sistema universitario de calidad con métodos de enseñanza desactualizados y que limitan el cambio educativo, especialmente cuando se requiere de innovaciones tecnológicas (Martelo, Franco y Oyola, 2020), las cuales deben permitir que el accionar del profesor sea accesible y esté adaptado a los requerimientos del contexto sociohistórico sobre el cual se produce el fenómeno educativo y que va más allá de la cobertura, financiamiento y variedad de la oferta, apuntando de manera oportuna y eficaz a las necesidades del estudiantado y al trabajo de aula gestionado desde el conocimiento de la multidimensionalidad curricular.

En resumen, las diferencias y/o debilidades se exacerban en la medida que los planteles no cuenten con equipos académicos expertos en educación superior. Así, puede acontecer que en algunas entidades los responsables de las plataformas educativas sean académicos expertos en alguna disciplina además de dominar las tecnologías educativas, en otros pueden ser profesionales con otras formaciones y sin perfil académicos e, incluso, puede acontecer que para algunas entidades sea más rentable contratar a empresas externas que, objetivamente, no conocen la realidad educativa, carreras, disciplinas y currículos. Dichos escenarios pudiesen ser una muestra de las profundas desigualdades educativas, las que se constituyen en un problema de inclusión y equidad circunscrita en la política pública. Según esto, la idea basal de concebir a la educación como "bien público", emerge como una demanda social, lo cual posibilita que el modelo dual (público-privado) sea cuestionado (Rama, 2012), por lo cual se justifica que las agencias estatales ejerzan una mayor regulación de la educación superior y sus currículos, ya que, ante el escenario de enseñanza virtual, el surgimiento de problemas educativos puede deberse, tanto a la poca claridad en las propuestas curriculares, lo cual conduce a la mala calidad de la educación (Rinesi, 2020), como a la existencia de plataformas mal gestionadas o la falta de idoneidad del profesorado, entre otros inconvenientes.

\section{Principios de aceptabilidad y adaptabilidad según el marco regulatorio nacional}

En democracia se firmaron pactos y convenios internacionales alusivos a los Derechos Humanos, lo que implicó el resguardo de los principios de aceptabilidad y adaptabilidad de la educación. Dicho de otra forma, el artículo $26^{\circ}$ de la Declaración Universal de Derechos Humanos; el artículo $13^{\circ}$ del Pacto Internacional de Derechos Económicos, Sociales y Culturales; y el Artículo $26^{\circ}$ de la Convención Americana de Derechos Humanos establecen que los sistemas educativos deben contar con una calidad aceptable, así como también tienen 
que estar adaptados a los requerimientos de la sociedad, lo cual debiese ser un requisito fundamental para efectos de aseguramiento de la calidad.

El Comité de Derechos Económicos, Sociales y Culturales plantea que el derecho a la educación se ubica en el centro, puesto que permite la consecución de otros derechos. Dicho de otra manera, la educación puede ser entendida como un derecho individual y social de aplicación directa e inmediata, puesto que tiene que estar al alcance de todas las personas y durante las diversas etapas de la vida.

El artículo 13 del Pacto Internacional de Derechos Económicos, Sociales y Culturales de Naciones Unidas establece que la calidad educativa es un derecho fundamental, por lo cual deben existir mínimos asegurados por una ley orgánica constitucional que permita el acceso igualitario en función de los méritos respectivos.

La reducción de desigualdades derivadas de circunstancias económicas, sociales, étnicas, de género o territoriales son obligaciones que contraen los Estados tras la firma de acuerdos, pactos o convenios de DDHH, por lo cual quedan obligados a brindar una educación de calidad. Así, la docencia virtual no puede estar alejada de ello, por lo cual deben existir políticas públicas que resguarden una calidad aceptable. Por otra parte, la adaptabilidad implica adaptarse al contexto y realidad del estudiantado. Por ende, ambos principios se asocian a la dimensión de metodología del trabajo docente y calidad de contenidos, siendo transversal a estos la sólida formación del profesorado, tanto en el área pedagógica como específica o disciplinar según la materia y carrera en la cual se desempeña.

Concretamente, en Chile, el discurso político oficial ha girado en torno al principio de accesibilidad o "beneficio" dirigido a los estudiantes provenientes de familias de los quintiles más pobres. Sin embargo, y en estricta alusión a la calidad, los informes internacionales realizados por la OCDE (2017) evidencian que los futuros profesionales reciben formaciones muy disminuidas y con resultados que están por debajo del promedio de la mencionada entidad.

Un referente específico de aceptabilidad y adaptabilidad de la calidad educativa en el nivel superior es la Ley de Aseguramiento de la Calidad de la Educación Superior -LAC(20.129)-, siendo la que posee mayor especificidad, puesto que dictamina lo que deben hacer las casas de estudios superiores para efectos de lograr acreditarse. Sin embargo, dicho proceso muestra también las diferencias y tensiones entre el Estado y las instituciones educativas, lo cual pudiese estar causado por la carencia de mecanismos efectivos de autocontrol por parte de dichas entidades (Brunner, 2017), puesto que, al asumir el Estado un rol "evaluador" (Neave, 2001) frente a un sistema con alto grado de privatización (Salazar y Leihy, 2017), variabilidad y dispersión de resultados, las acciones de control se complejizan y las demandas de la sociedad se polarizan. Por lo mismo, no necesariamente los sistemas de acreditación y sus indicadores son un reflejo real y potente de la calidad percibida por los estudiantes, especialmente en un momento histórico, causado por Covid, en el cual se requiere de decisiones pedagógicas eficientes y eficaces por parte de los planteles y sus equipos académicos.

Pese a la existencia de mecanismos de control en ES, lo cierto es que el Estado chileno no asume un rol social efectivo, puesto que, desde la dictadura iniciada en 1973, se instala el 
modelo neoliberal. Así, la Constitución de 1980 consolida el principio de subsidiariedad estatal, por ende, el Estado asumió un rol de fiscalizador u observante, lo cual ha permitido que las entidades tengan un amplio espacio de autonomía, así como también ha convertido a la educación en un bien de mercado (Salazar y Leihy, 2017). El artículo $1^{\circ}$ de la Ley General de Educación de 2009, prescribe el deber estatal para propender al aseguramiento de una educación de calidad. Sin embargo, propender no implica asegurar un derecho fundamental. Así, el hito más significativo en cuanto al rol subsidiario del Estado en educación superior es la publicación de la Ley 20.129, puesto que, determina las dimensiones a ser evaluadas, tanto para instituciones, como para programas de pregrado y postgrado, -siendo la acreditación obligatoria de manera exclusiva para las carreras de pedagogía y medicina desde 2006-, lo cierto es que el proceso es ejecutado por agencias privadas con fines de lucro, lo cual cambió en 2021, puesto que, tras la publicación de la Ley de Educación Superior de 2018 (N.o 21.091), esto será ejecutado por la CNA.

La calidad global de la educación superior chilena está regulada por la Ley 20.129, siendo el Comité de Coordinación del Sistema Nacional de Aseguramiento de la Calidad de la Educación Superior (SINACES), el encargado de coordinar a los cuatro órganos que le dan vida, y esto son: la CNA, encargada de evaluar, acreditar y promover la calidad de las instituciones y sus programas, además de “...ejecutar y promover acciones para el mejoramiento continuo de la calidad de las instituciones de Educación Superior..." (Ley 20.129); La Superintendencia de Educación Superior (SES), cuyo rol es fiscalizar y supervigilar el cumplimiento del marco normativo y estatutos declarados, siendo su principal preocupación la dimensión financiera (SES, 2021); El Consejo Nacional de Educación (CNED), que tiene como tarea acompañar y apoyar a las instituciones y programas para su mejora, realizando el licenciamiento, supervisión y supervigilancia de ciertas decisiones tomadas por las otros órganos del sistema (Ley 20.129); y la Subsecretaría de Educación Superior (Subses), creada por la Ley 21.091, que es un órgano que colabora con el del Ministro de Educación en la "elaboración, coordinación, ejecución y evaluación de políticas y programas para la educación superior" (Subses, 2021a).

La Ley 21.091 -Ley de Educación Superior (LES)- define a la calidad como un principio orientador hacia la excelencia y la consecución de los propósitos institucionales, siendo el SINACES el encargado de velar por el aprendizaje de los estudiantes. Con ello, se pretende que las IES puedan desarrollar procesos de formación completos y pertinentes, asegurando la autonomía para cada entidad (Subses, 2021).

Durante la pandemia, el Comité del SINACES publicó en junio de 2020 un documento con las orientaciones para el proceso formativo, el cual se sustenta en recomendaciones, señalando expresamente que "no posee carácter legal vinculante"(Subses, 2021b, p. 2), por ende, no necesariamente está alineado con otros mecanismos del Sistema.

Según lo anterior, y asumiendo el rol de la Subses respecto a la pertinencia educativa, es plausible tensionar el factor docente y aspectos pedagógicos teniendo como referente los principios de aceptabilidad y adaptabilidad. Dicho de otra manera, la calidad de la docencia presencial y online deben ser observadas por las agencias estatales. Sin embargo, para poder realizar dicho análisis, se requiere que la política pública educativa declare expresamente los 
aspectos a observar, lo que se espera de las entidades de manera general y de los académicos en particular, y los modos a través de los cuales se llevará a cabo tal examinación.

El rol subsidiario el Estado, conllevó a la estandarización de procesos y la consolidación de la racionalidad política neoliberal (Oliva y Gascón, 2016), regulando procedimientos y, a través de estos, detentando la capacidad de intervenir en las estructuras por medio de la entrega de aportes económicos a las entidades públicas y privadas, pero, por otra parte, la recepción de recursos junto con el aseguramiento de la calidad implica que los proyectos educativos y currículos deban acomodarse a los designios de agencias estatales, con marcadas influencias internacionales, desdibujándose los sellos institucionales y haciendo que la pertinencia y adaptabilidad del currículo estén invisibilizadas. Por lo mismo, surge la duda si la docencia es de calidad y, objetivamente, al no ser de óptimo nivel, entonces, ante la virtualización de las clases, y siguiendo a Martelo, Franco y Oyola (2020), ello se hará más evidente en planteles de baja selectividad, provocando que los estudiantes con menor capital sociocultural, y que suelen matricularse en entidades de menor prestigio, serán quienes recibirán formaciones débiles, con contenidos precarios, metodologías docentes desajustadas y con profesores menos idóneos y que detentan mediano o bajo dominio disciplinar y/o pedagógico.

Los requerimientos internacionales en materia de DDHH y tendencias de internacionalización de la educación superior, han provocado que, desde el retorno de la democracia, las políticas públicas educativas chilenas recorran un camino fisurado y pendular que da cuenta de racionalidades de diverso orden y con medidas ambivalentes que, por un lado, aportan recursos a las entidades públicas, pero también apoyan el desarrollo de instituciones privadas de disímil calidad, generando facilidades para el licenciamiento institucional (Salazar y Rifo Melo, 2020). De este modo, el sistema chileno creció inorgánicamente, propiciando ello la desarticulación del discurso educativo oficial, el cual fue colonizado y conquistado por la econometría y remitiendo los problemas educativos al financiamiento, siendo la teoría económica del capital humano el discurso que prima en las agencias estatales (De Moura y Levy, 1997; Brunner et al. 2005; en Salazar y Rifo Melo, 2020) y que concibe a la educación superior como bien de consumo, instalándose una política sectorial que, desde 1980, se funda en la comercialización de un derecho y bien común (Silva, 2015; en Salazar y Rifo Melo, 2020).

\section{Discurso y calidad educativa}

Diversas perspectivas teóricas han manifestado interés por la dimensión política del discurso. Así, los análisis discursivos de Alba (2015); Laclau y Mouffe (2014); van Dijk, (2016, 2017) y Fairclough (2018) se centran en las fijaciones parciales de los significados construidos en las relaciones sociales desde un enfoque interdisciplinar que da cuenta de hegemonías y subjetivaciones.

Los estudios críticos analizan discursivamente las relaciones sociales de dominación y resistencia, pero su objetivo no es alcanzar la verdad, sino más bien comprender las distintas posibilidades que emergen desde los distintos textos y sus fisuras, considerando como relevante el contexto sociohistórico de producción (van Dijk, 2016). 
El Análisis Crítico de Discurso (ACD) asume que todo texto genera efectos o imbricación, siendo un campo de investigación que se ha desarrollado con fuerza desde los 90's en adelante, especialmente con la ayuda de los conceptos desarrollados por Norman Fairclough y Teun Van Dijk, quienes se han adentrado en las tramas discursivas considerando el contexto social y estructuras mentales de los hablantes, quienes operan como sujetos, pero también como representantes de grupos de poder. Es decir, lo hegemónico, las construcciones sociales y los modelos mentales que subyacen a lo que dicen y hacen las personas son elementos claves para comprender este tipo de análisis, puesto que se adentra en las tramas discursivas y los modos de como éstas develan las relaciones de los sujetos y el poder.

De igual modo, los significados de un discurso algunas veces no están expresados linealmente en el texto, por lo tanto, se debe recurrir a diversas estrategias para interpretarlos, sin dejar de lado sus condiciones de producción. Así, las macroestructuras posibilitan definir la coherencia ideológica de un texto (van Dijk, 2017), sin olvidar que, para que sean discursos ideológicos, estos no pueden ser dichos por el análisis del mismo, sino por una teoría social, histórica y/o económica, la cual emerge en los textos, fruto de la interacción en un determinado contexto sociohistórico (van Dijk, 2017). Por lo mismo, el ACD permite conocer quiénes tienen real acceso al discurso público asociado a la docencia virtual. Dicho de otra forma, quiénes son los que efectivamente pueden tener un rol activo y controlador, lo cual posibilita el ejercicio del poder según los discursos que se controlan.

Concretamente, el ACD permite develar los tránsitos del poder, sus estructuras y sus modos de operación. Por lo mismo, es importante reconocer, tanto quienes tienen acceso, como quienes no tienen acceso al discurso público y las ideologías predominantes, las que en definitiva permiten la construcción discursiva en una determinada sociedad, según el contexto sociohistórico en el cual emerge el fenómeno, y que dan cuenta de los modelos mentales hegemónicos.

El estudio crítico del discurso se constituye en una herramienta analítica que permite dar cuenta de cómo operan lingüísticamente las relaciones de poder y tendencias dominantes, así como también devela contrahegemonías y disidencias (van Dijk, 2016; 2017). El control se asocia a limitar la libertad de otros a través del control de la mente (van Dijk, 2016; 2017), siendo esto una forma de poder no coercitivo que apunta hacia los modelos mentales de las personas, haciendo que estas actúen de un modo esperado. Así, el discurso se constituye en práctica social y en medio de control de los actos de las personas, por ello, saber lo que se dice respecto a la calidad de la docencia virtual, implica develar la ideología que subyace a la estructuración del actual sistema de educación superior.

En línea con Laclau (2020), la hegemonía es una forma de construcción de "lo político", por lo mismo, el discurso político oficial referido a la calidad de la docencia virtual en pandemia está cruzado por el estallido social, siendo ambos fenómenos sociales que implican acciones de poder desplegadas de diversos modos y en función de distintos tipos de recursos. Por lo mismo, cada hecho sociohistórico genera aprendizajes colectivos en las entidades educacionales (Burgos, 2017), los cuales van más allá del currículo prescrito, puesto que son los sujetos quienes elaboran un vínculo psicosocial con la institución formadora. En consecuencia, bajo este escenario de aulas virtuales se produce un discurso que lleva 
inmersas la inclusión y exclusión, lo cual evidencia las relaciones de poder entre grupos sociales (Burgos, 2017) y que está performado según lo prescrito por las agencias estatales.

El objetivo del ACD es evidenciar las líneas argumentativas utilizadas por los grupos sociales que detentan el poder y con las cuales justifican y legitiman la exclusión, discriminación o explotación hacia el exogrupo. Por lo mismo, se centra en develar las ideologías subyacentes al texto y que se presentan como un conjunto de creencias y opiniones (van Dijk, 2016).

En cuanto a las estrategias ideológicas de mayor prevalencia en el ACD, la autorrepresentación positiva y la representación negativa del otro suelen ser las más utilizadas, puesto que dan mayores posibilidades de ejemplificación y connotación de hechos, personas o circunstancias sociales. Dichas estrategias suelen enfatizar los rasgos positivos y generar silencios u ocultamientos de lo malo. De igual modo, resaltan los aspectos malos de los otros y ocultan lo positivo, lo que, en esta línea de trabajo, se conoce como cuadrado ideológico (Van Dijk, 1998).

Concretamente, las demandas sociales suelen transformarse en enunciados de política pública y que emergen como leyes, disposiciones, lineamientos u orientaciones que, al ser emitidos por las agencias estatales, dejan entrever el poder, es decir, quienes son los grupos que efectivamente dominan y controlan a la sociedad.

La docencia virtual no es un hecho aislado, puesto que se enmarca en un contexto histórico. Así, Espinosa (2015) precisa que las políticas públicas educativas no son un comportamiento azaroso, puesto que se inscriben dentro de una tendencia ideológica. Es decir, no son acciones aisladas tomadas por los gobernantes de turno, sino que emergen para un fin específico y que, en muchos casos, aunque remitan a temas educacionales, el propósito real no está en dicho tema.

La política curricular se presenta como un modo discursivo que permite seleccionar, ordenar y cambiar el currículum, por ende, posee códigos que no solamente remiten a la dimensión pedagógico sino también posee un fuerte arraigo político e ideológico (Gimeno Sacristán, 1988). Según esto, lo que se dice y no se dice respecto a la dimensión curricular permiten entrever las ideologías subyacentes de los grupos de poder que efectivamente manejan el sistema educativo.

En resumen, discursivamente el neoliberalismo ha conllevado la economización y mercantilización de diversos comportamientos sociales (Ball, 2016). Por lo mismo, este estudio tiene como sustento teórico, metodológico y axiológico la estructuración y operación discursiva en sociedades neoliberales, para lo cual se identificaron y describieron los elementos que dan cuenta de una política pública educativa anclada en lo hegemónico que, por medio de cuestionamientos e interpelaciones se desencripta, emergiendo posibilidades de cambio. 


\section{MÉTODO}

\section{Tipo de estudio}

La investigación desarrollada es cualitativa, exploratorio-descriptiva y sustentada en la estrategia del análisis crítico del discurso (van Dijk, 2016, 2017).

El corpus investigativo estuvo conformado por: el documento Principios Orientadores para La Educación Superior Chilena Durante la Pandemia (Subses, 2020b); el Plan de Acción MNEDUC para Instituciones de Educación Superior (MINEDUC, 2020a); y Orientaciones Generales para la Educación a Distancia en Educación Superior, constituidas por tres documentos: 1-Consideraciones para guiar el aprendizaje de los estudiantes; 2Consideraciones para el diseño de evaluaciones a distancia sin el uso de proctorios; y 3Orientaciones generales para el desarrollo de evaluaciones activas a distancia (MINEDUC, 2020b).

\section{Estrategia analítica}

El estudio se sustenta en el análisis crítico del discurso, el cual se constituye en una herramienta analítica que permite dar cuenta de cómo operan lingüísticamente las relaciones de poder y tendencias dominantes, así como también devela contrahegemonías y disidencias (van Dijk, 2016; 2017).

Buenfil Burgos (2009) afirma que el ACD también es un análisis histórico, puesto que se adentra en la construcción de significados y en la transformación histórica del significado de los hechos. Por lo anterior, la validez del análisis se encuentra en los conceptos, su articulación, el modo de leer las claves que emergen de los textos y la construcción de vinculaciones históricas por parte del autor. Expresado de otro modo, el análisis crítico del discurso permite conocer los sentidos históricos de y

Específicamente, la búsqueda se indicios, literalidades, silencios u omisiones son los modos a través de los cuales lo textos hablan de los posicionamientos ideológicos que rigen el accionar de agencias estatales y planteles, por lo mismo, el objeto de estudio remite a lo prescrito desde el nivel central estatal, para así observar los modos a través de los cuales se instala lo hegemónico, es decir, aquello que va más allá de lo señalado y que emerge como principio rector de lo que se hace (o lo que no se hace) para poder brindar una docencia virtual de calidad.

Es importante señalar que los textos escogidos se seleccionaron de acuerdo con el criterio de temporalidad y atingencia, es decir, que fuesen publicados al inicio de la pandemia y/o que sean documentos que regulan el accionar pedagógico en ES, para lo cual se eligieron aquellos que remiten a la calidad de la docencia virtual.

El análisis de los textos se basa en la revisión de los temas o contenidos tratados en los documentos que orientan el quehacer docente durante la pandemia y la identificación de estrategias discursivas específicas asociadas a la saturación positiva de los conceptos (van Dijk, 2016; 2017) y que intentan adjudicarles propiedades y funciones de solución al problema de la docencia virtual. 
En resumen, el ACD representa una forma de razonamiento dialéctico orientada a criticar normativas y a explicar, a partir de sus configuraciones lingüísticas, las condiciones sociales existentes para luego llamar a la acción social comprometida con la transformación de aquellas condiciones que oprimen cotidianamente a millones de seres humanos (van Dijk; 2017; Fairclough, 2018; en Palacios, Hidalgo, Suárez y Saavedra, 2020).

\section{Procedimiento}

La selección del corpus se realizó por muestreo intencional, para lo cual se realizó la búsqueda de textos oficiales en las páginas del Ministerio de Educación, tomando como criterio nominal "docencia virtual" y "calidad".

El análisis comenzó con la selección de fragmentos textuales en los documentos oficiales que de algún modo remitieron a un problema social, es decir, a la docencia virtual durante la pandemia. Así, el discurso oficial operó como un razonamiento práctico que, desde el poder, da respuesta (o no) a una demanda ciudadana.

En segundo lugar, se buscaron indicios o modos de hegemonía, es decir, modos discursivos que intentan posicionar a un determinado grupo de poder, con sus respectivas ideologías y estrategias discursivas.

Finalmente, se articularon respuestas referidas a los elementos ideológicos que definen el uso del discurso de las agencias estatales durante el plan de supervisión de la virtualización de la docencia virtual en pandemia.

El acento o clave analítica estuvo enfocado en lo expresado y no expresado en los textos estudiados respecto de la docencia virtual, tomando como categorías analíticas los factores asociados a la actividad docente por Martelo, Franco y Oyola (2020) y que aluden a: Calidad de contenidos; Metodología de trabajo docente; y Sólida formación del profesorado, las cuales han sido sugeridas, tanto por los hallazgos de los investigadores, así como también por las líneas argumentativas propuestas o develadas por los mismos documentos estudiados.

Tras la definición de estas tres categorías se procedió a la búsqueda de referentes específicos que diesen cuenta de ellos y que, además estuviesen en consonancia con los principios de aceptabilidad y adaptabilidad. Es decir, se buscaron literalidades, así como también fisuras, entramados, omisiones o silencios que diesen cuenta de hegemonías, relaciones de poder y de los posibles grados de autonomía que subyacen a toda estructura de dominación. Dicha búsqueda fue realizada desde una perspectiva crítica que permitiese mostrar, tanto la invisibilización de la calidad de la docencia, como del currículo, tomando como ejes conductores de hallazgos las categorías establecidas por Martelo, Franco y Oyola (2020). 


\section{RESULTADOS Y ANÁLISIS}

La primera categoría analizada remite a la calidad de contenidos (Martelo, Franco y Oyola, 2020), encontrándose algunos referentes específicos en el documento denominado los Principios Orientadores para La Educación Superior Chilena Durante la Pandemia (Subses, 2020b), el cual detalla las sugerencias que emanan desde el nivel central para el desarrollo de la docencia en las IES durante la pandemia, estableciendo como directriz "seleccionar los aprendizajes esenciales", declarando expresamente el "desplazamiento lo máximo posible" de las actividades prácticas (Subses, 2020b:3). En dicho documento también se hace énfasis de manera nominal en el desarrollo de competencias digitales y en el ajuste de los planes de estudio. De igual forma, se menciona que la priorización de los aspectos teóricos y el futuro ajuste de los modelos formativos son las tareas que deben realizar los planteles.

En la misma línea argumentativa, el Plan de Acción MINEDUC para Instituciones de Educación Superior (MINEDUC, 2020a) se remite a dar a conocer el acuerdo celebrado entre el Ministerio de Educación (MINEDUC) y la empresa Google; el aporte económico estatal para el desarrollo de proyectos de formación virtual, mayoritariamente realizados por megaempresas tecnológicas internacionales; y el impulso de alianzas estratégicas entre planteles para así difundir "buenas prácticas". Dicho de otra forma, no establece marcos teóricos, lineamientos estratégicos y/o acciones formativas concretas que permitan al cuerpo académico desarrollar una docencia virtual de calidad.

El documento denominado "Orientaciones generales para guiar el aprendizaje de los estudiantes a distancia en instituciones de educación superior" (MINEDUC, 2020b) se remiten a la entrega de en un listado de plataformas y redes sociales que permiten mantener el contacto con los estudiantes, sin detallar el modo de uso del recurso pedagógico, área disciplinar o tipo de docencia que de mejor manera se adapta a cada uno de ellos. En alusión a las "buenas prácticas", el documento establece una serie de sugerencias logísticas que en ningún caso remiten a la dimensión curricular y tampoco presentan una justificación teórica desde la didáctica. De igual forma, las consideraciones alusivas al diseño de evaluaciones siguen la misma lógica, por lo tanto, listan una serie de sugerencias prácticas o logísticas, sin evidenciar diferencias entre disciplinas o tipos de carreras, no existiendo una fundamentación teórica para justificar su uso y no especificando ámbitos de acción según tipologías de asignaturas, planteles, estudiantes, etc.

El segundo aspecto estudiado corresponde a metodología de trabajo docente, siendo una dimensión que, desde el marco normativo nacional, no ha sido consistentemente definida. Es así, como el discurso oficial no entrega mayores evidencias de qué y cómo se desarrolla la docencia de calidad.

Específicamente, los documentos ministeriales que entregan diversas consideraciones y orientaciones durante la pandemia se remiten a sugerir la adaptabilidad de los "procesos de enseñanza aprendizaje" (Subses, 2020b: 3), haciendo hincapié en el desarrollo de ajustes a las evaluaciones. Sin embargo, no existe una definición o sugerencia teórico-epistemológica que permita la verdadera comprensión y óptimo desarrollo de lo declarado. Dicho de otra forma, los documentos enuncian una serie de posibles acciones, sin dar mayores argumentaciones o líneas de trabajo que permitan a los docentes comprender los reales alcances, modos, apropiaciones y dominios que implica la docencia virtual. 
El tercer tópico de análisis fue la sólida formación del profesorado o dominio pedagógico y disciplinar del docente, lo cual, a la luz de los discursos analizados, no está expresado. Es decir, es una dimensión invisibilizada por la política pública durante la pandemia. Es decir, no se alude a las características del profesorado, el tiempo que se debe destinar a la preparación de actividades, metodología de aula, etc.

Las tres dimensiones estudiadas, y que se aproximan al constructo de calidad de la docencia virtual enunciadas a partir de los hallazgos de Martelo, Franco y Oyola (2020), permitieron distinguir dos aspectos relevantes alusivos a la calidad de la docencia virtual:

Primeramente, se puede observar cómo las tendencias internacionales, políticas supranacionales y marco normativo nacional "llegan al aula". Es decir, los modos a través de los cuales el discurso político oficial se alinea a dichas macrotendencias, constituyéndose en un elemento que guía el accionar de las IES. Así, el discurso oficial promueve el uso de plataformas en las cuales están comprometidos intereses de mercado. Según esto, es plausible señalar que dicho discurso efectivamente intenta instalarse en los planteles, sin embargo, a través de dicha instalación se observa la laxitud de las políticas públicas.

Las disposiciones emanadas desde las agencias estatales poseen inexistentes argumentos teóricos que permitan a las instituciones desarrollar acciones pedagógicas de calidad, puesto que, tanto los referentes específicos de calidad (textos legales), como la red de agencias que conforman el SINACES, están ancladas al paradigma que privilegia a la enseñanza y no el aprendizaje efectivo de los estudiantes. De igual forma, los documentos intentan impulsar el uso de ciertas empresas de soporte informático y recursos tecnológicos que, aun cuando pueden ser ventajosos para el aprendizaje, estos no son descritos desde una perspectiva pedagógica, por ende, los discursos oficiales intentan seguir la tendencia hegemónica sin encontrar una justificación teórica-epistemológica coherente y atingente a la realidad de cada entidad.

En segundo lugar, los textos enunciados como orientaciones y las leyes que regulan la educación superior chilena mencionan la aceptabilidad y adaptabilidad de un modo declarativo pero que no encuentra correlatos dentro de la institucionalidad. Dicho de otra forma, el modelo que opera en Chile, y en la mayoría de los países de Latinoamérica, no ha puesto el acento en el autoaprendizaje, promovido por docentes que tengan un perfil propicio para aquello. Más aún, no es un requisito fundamental para el desarrollo de actividades lectivas en IES contar con formación en el campo educativo.

Es importante señalar que, en relación a la calidad de la enseñanza, la Ley 20.129 establece que "los procesos de acreditación institucional deberán considerar... Docencia y resultados del proceso de formación: Debe considerar las políticas y mecanismos institucionales orientados al desarrollo de una función formativa de calidad, los que se deberán recoger en la formulación del modelo educativo." (art. 18). Sin embargo, los procedimientos, instrumentos, tareas asociadas y formación e idoneidad de los profesionales encargados de realizar dichas actividades no han sido sugeridas por la ley, lo cual puede constituirse en un entrampe para el aseguramiento de la calidad, especialmente porque ello está en manos de las propias entidades. Dicho de otro modo, el desarrollo de dichos procesos no augura que estos gocen de pertinencia y calidad, por lo tanto, al estar mal ejecutados, las decisiones que 
se tomen a la luz de aquello pudiesen ser espurias y afectar de forma directa a los estudiantes, en especial cuando los procesos pedagógicos están en plataformas que no necesariamente son administradas por expertos disciplinares y curriculares.

Cabe precisar que en la dimensión de docencia de pregrado la nueva ley incluye los siguientes criterios:

1. Relación entre la definición de los propósitos y objetivos institucionales y la organización de la docencia de pregrado: áreas del conocimiento cubiertas y las que se espera incorporar en el futuro, tipo de programas, población objetivo, cobertura geográfica, ajuste entre las declaraciones de propósitos y la oferta de la institución.

2. Mecanismos utilizados para la definición de perfiles de egreso, el diseño y actualización curricular, la asignación de recursos docentes, didácticos, físicos y financieros a los programas ofrecidos, contemplando asimismo la forma en que se evalúa la consistencia entre los propósitos definidos, las decisiones adoptadas y los resultados obtenidos.

3. Mecanismos para definir, evaluar y corregir si es necesario, el proceso de enseñanza, contemplando los sistemas de selección y/o admisión, los métodos pedagógicos y su relación con los requisitos de formación de los respectivos programas y las características de los estudiantes admitidos a ellos, los procedimientos de evaluación del aprendizaje y el uso eficaz de elementos tecnológicos en la enseñanza.

4. Los mecanismos para identificar las necesidades de recursos humanos, así como las estrategias seguidas para reclutar, evaluar y perfeccionar al cuerpo docente, técnico y administrativo asignado a los programas.

5. Los mecanismos utilizados para evaluar el servicio prestado a los estudiantes, considerando tanto las características de su progresión dentro de los programas como la consideración de sus opiniones para el mejoramiento de los servicios prestados" (CNA, 2018).

Específicamente, al analizar la normativa se observa que ella apunta más bien a la existencia de ciertos aspectos inherentes al quehacer educativo desde un enfoque administrativo y burocrático, sin dar cuenta de las necesidades propias de un diseño curricular óptimo, como, por ejemplo, que exista la obligatoriedad de tener diversas tipologías de diseños y mecanismos teórico-prácticos de ajustes según el campo o campos disciplinares desarrollados por las instituciones; que las entidades declaren abiertamente los enfoques epistemológicos utilizados, justificando ello con estudios certeros respecto al perfil de sus estudiantes; que exista investigación interna con metodologías validadas para la toma de decisión; que las actividades e instrumentos evaluativos sean de calidad, atingentes a la disciplina y con la validez pertinente, etc. Expresado de otro modo, la ley establece lo que debe exigirse a los planteles, sin embargo, no establece la calidad y pertinencia de ello, olvidando que un mal proceso y/o instrumento arroja resultados erróneos, lo cual objetivamente afecta directamente a los estudiantes, sus logros de aprendizaje efectivo y la empleabilidad, entre otros aspectos.

El corpus analizado permite develar un nudo crítico de la política pública educativa, el cual remite a que la concepción de la calidad de la enseñanza virtual se construye y reproduce a partir de la calidad de la educación superior en general. Es decir, el discurso oficial no 
reconoce diferencias, por lo cual, la calidad en formato virtual no posee una definición propia. Esto, más que dar cuenta de una omisión, remite a los fines o propósitos reales del sistema formativo. Es decir, pareciera ser que lo relevante es la existencia del sistema, no si este responde o no a las demandas ciudadanas y/o necesidades específicas de los estudiantes. Dicho de otra forma, las tendencias e intereses permiten erigir un sistema en donde el oferente del servicio es la parte beneficiada, mientras que docentes y estudiantes están invisibilizados, lo cual, resulta aún más evidente cuando la docencia se realiza a través de plataformas virtuales.

Por otra parte, continuamente los documentos orientadores utilizan la estrategia de la autorrepresentación positiva, por lo cual, sugieren el uso de determinadas plataformas, sin aludir a las debilidades y dificultades asociadas a su implementación, por ejemplo, que la instalación y utilización de éstas requiere de equipos y conexiones de internet de óptima calidad. Es decir, se ocultan los problemas que pueden vivenciar docentes y estudiantes y solamente se alude a las posibles ventajas para las instituciones para efectos de cumplir con las programaciones y así tener evidencias según lo prescrito por el sistema de aseguramiento de la calidad para acreditación.

También llama la atención que dentro de las directrices emanadas desde las agencias estatales se sugiera la suspensión de actividades prácticas, la selección de contenidos y de cierta manera la minimización del quehacer docente. Al respecto, surge la duda si efectivamente ello tiene alguna justificación pedagógica, lo cual no se expresa en los textos, 0 aquello es un modo de justificar la disminución de contrataciones docentes. Es decir, una medida de índole financiera que permite destinar los recursos económicos asociados a la contratación de docentes a otros fines, como, por ejemplo, la celebración de contratos con empresas proveedoras de servicios informáticos. Dicho de otro modo, precarizar el trabajo del profesor, en pro de favorecer a empresas y/o grupos de poder.

Según lo anterior, se debe recordar que objetivo del ACD es evidenciar las líneas argumentativas utilizadas por los grupos sociales que detentan el poder y con las cuales justifican y legitiman la exclusión, discriminación o explotación hacia el exogrupo. Por lo mismo, se centra en develar las ideologías subyacentes al texto y que se presentan como un conjunto de creencias y opiniones (van Dijk, 2016). Así, resaltar el uso de plataformas, invisibilizar el trabajo docente y connotar positivamente la disminución de contenidos y suspensión de actividades prácticas, no son solamente acciones, sino también operan como estrategias discursivas que intentan posicionar los intereses de un determinado grupo de poder, es decir, de los empresarios vinculados directa e indirectamente con el sistema de ES.

Por otra parte, la estrategia de la representación negativa del otro se manifiesta ocultando lo positivo. Por lo mismo, el cuadrado ideológico (Van Dijk, 1998) da cuenta de lo visible, constituido por los oferentes y la existencia del servicio educativo bajo cualquier escenario (aulas físicas y virtuales), y lo invisible, es decir, los docentes, equipos pedagógicos y estudiantes, con sus respectivos intereses y necesidades, las que cambian según tipo de plantel y carrera.

Se observa que los documentos aluden a la acreditación desde un enfoque enfoques tecnocrático, con una jerga que remite a disciplinas distintas a la pedagógica y que asumen la existencia de un mercado supeditado a las reglas de la competitividad entre planteles, por 
ende, el uso plataformas virtuales también entra en este juego intercategorial de jerarquías y atributos de marca y no desde una concepción de la educación como un derecho social.

Por otra parte, la carencia de articulación conceptual alusiva a la docencia virtual y su comprensión desde una concepción crítica es una dificultad que se manifiesta en lo no dicho en los textos estudiados. Por lo mismo, una debilidad para la implementación y evaluación de la docencia virtual es la inexistencia de un marco teórico que permita la organización de la enseñanza (García Plana y Taberna Torres, 2020). Así, gestores y profesores, probablemente sin formación específica para el desarrollo de procesos pedagógicocurriculares virtuales, tuvieron que adoptar en pandemia un nuevo paradigma formativo, puesto que, cada actividad es en sí misma una evaluación del rendimiento o avance individual. Ello requiere de constante retroalimentación, lo cual es complejo, pudiendo acontecer que los administradores de los planteles y aulas virtuales decidan incorporar una cantidad excesiva de estudiantes, imposibilitando dicha retroalimentación. De igual forma, también se ha pesquisado como problema el exceso de contenidos, puesto que las plataformas poseen una capacidad que permite sobrepasarse (García Plana y Taberna Torres, 2020) o, lo que es peor, son administradas por personas que no conocen el currículo específico de cada carrera, por ende, piden cierto tipo y cantidad de materiales pedagógicos a los docentes que, en muchos casos, no tienen justificación o anclaje teórico- práctico con la asignatura.

En pandemia resulta complejo erigir un sistema universitario de calidad con métodos de enseñanza desactualizados y que limitan el cambio educativo, especialmente cuando se requiere de innovaciones tecnológicas (Martelo, Franco y Oyola, 2020), las cuales deben permitir que el accionar del profesor sea accesible y esté adaptado a los requerimientos del contexto sociohistórico sobre el cual se produce el fenómeno educativo y que va más allá de la cobertura, financiamiento y variedad de la oferta, apuntando de manera oportuna y eficaz a las necesidades del estudiantado y al trabajo de aula gestionado desde el conocimiento de la multidimensionalidad curricular.

Es llamativo que los textos publicados en pandemia consideren que esta es una situación extraordinaria y que, por ende, las orientaciones que dan las agencias estatales sean medidas extraordinarias frente a la contingencia, puesto que, es de conocimiento mundial que el Covid es un fenómeno de data de expiración desconocida. Por lo mismo, sugerir una precarización o disminución de contenidos y desplazamiento o suspensión de actividades prácticas pareciera ser una medida que no se comprende desde la dimensión educativa, pero sí pudiese tener un marco explicativo si es que el interés está en proteger y/o rentabilizar el negocio educativo. Es decir, se posiciona y justifican las decisiones de algunos planteles para, por ejemplo, desvincular docentes, especialmente quienes colaboran en actividades prácticas, y, para ello, se puede justificar aquello desde el discurso oficial, el que tácitamente valida este tipo de decisiones.

La revisión documental permite precisar que el concepto de calidad de la docencia virtual en educación superior no está explicitado en las políticas públicas. De igual modo, implícitamente el concepto es entendido desde la lógica del mercado y no se constituye por medio de un lenguaje que remita a lo educativo. Por el contrario, puesto que, debido a la existencia de mecanismos de evaluación y gestión de la calidad sustentados en la acreditación 
y accountability, la dimensión pedagógico-curricular se invisibiliza. Por lo mismo, en tiempos de pandemia, la existencia de recursos destinados a la adquisición o contratación de recursos informáticos adquiere mayor realce, por ende, el qué, cómo y quién enseña no resulta ser relevante para la política pública.

En resumen, las diferencias y/o debilidades se exacerban en la medida que los planteles no cuenten con equipos académicos expertos en educación superior. Así, puede acontecer que en algunas entidades los responsables de las plataformas educativas sean académicos expertos en alguna disciplina además de dominar las tecnologías educativas, en otros pueden ser profesionales con otras formaciones y sin perfil académicos e, incluso, puede acontecer que para algunas entidades sea más rentable contratar a empresas externas que, objetivamente, no conocen la realidad educativa, carreras, disciplinas y currículos. Dichos escenarios pudiesen ser una muestra de las profundas desigualdades educativas, las que se constituyen en un problema de inclusión y equidad circunscrita en la política pública. Según esto, la idea basal de concebir a la educación como "bien público", emerge como una demanda social, lo cual posibilita que el modelo dual (público-privado) sea cuestionado (Rama, 2012), por lo cual se justifica que las agencias estatales ejerzan una mayor regulación de la educación superior y sus currículos, ya que, ante el escenario de enseñanza virtual, el surgimiento de problemas educativos puede deberse, tanto a la poca claridad en las propuestas curriculares, lo cual conduce a la mala calidad de la educación (Rinesi, 2020), como a la existencia de plataformas mal gestionadas o la falta de idoneidad del profesorado, entre otros inconvenientes.

\section{CONCLUSIONES}

La investigación centrada en el análisis del discurso oficial respecto a la calidad de la docencia virtual como derecho social y sustentada en los principios de adaptabilidad y aceptabilidad en educación superior, ha posibilitado enfatizar en dos aspectos característicos de la formación universitaria chilena y que, objetivamente, afectan la calidad global, estos son: el crecimiento del sistema privado, avalado en el rol subsidiario del estado, y la invisibilización de la dimensión pedagógico curricular en el nivel superior. Dicho de otra manera, la libre creación de planteles, los cuales responden a los respectivos intereses neoliberales de ciertos grupos de poder que controlan el mercado universitario, y la subsidiariedad estatal que, como principio constitucional, propicia la autonomía para que cada institución defina sus modos y prácticas pedagógicas, se transforman en oportunidades para algunos y amenazas para otros. Así, los grupos empresariales pueden instalar nuevas necesidades de mercado, como pudiesen ser las plataformas educativas, y ocultar problemas sociales, como, por ejemplo, las brechas y asimetrías existentes entre planteles debido a las debilidades formativas que se replican y enquistan en la sociedad, generando profesionales de primer, segundo y hasta tercer nivel.

Desde la dictadura el discurso de la política educativa ha estado alineado con el sometimiento de la educación superior a las leyes del mercado, para lo cual se subsidia a la demanda. Por otra parte, y aunque se ha intentado cambiar y frenar el avance progresivo de los aranceles, es innegable que la educación chilena posee aranceles muy altos, sin asegurar que efectivamente la formación brindad sea de calidad. Por lo mismo, en pandemia, la 
sugerencia de emanada de los documentos oficiales alusivas a la adaptación de contenidos, que en términos prácticos implica la reducción de estos, así como el desplazamiento o eliminación de actividades prácticas, emerge como un acto de injusticia social.

Los fundamentos ideológicos surgidos desde la dictadura han propiciado la construcción de una lógica que da validez al sistema. Así, ha primado la dimensión financiera, por lo cual dichos elementos ideológicos están presentes en el discurso oficial neoliberal, por lo tanto, el acento está puesto en el costo y financiamiento de la ES, no en el currículo.

Las referencias a la calidad de la docencia virtual, expresada a través de las directrices emanadas desde las agencias estatales durante la pandemia por Covid, son una nueva evidencia de la invisibilización de la dimensión curricular. Según ello, dicha calidad no está representada, operacionalizada o definida en ningún dispositivo, por lo cual la aceptabilidad y adaptabilidad de los procesos formativos no están garantizadas, afectando con ello derechos fundamentales de los estudiantes.

Los resultados del estudio muestran la inexistencia de marcos referenciales robustos que permitan conocer, comprender y gestionar la calidad de los procesos curriculares, siendo la acción docente un componente fundamental, pero que queda remitido a aspectos declarativos, los cuales no permiten la generación de políticas certeras que aseguren la calidad de la docencia en todas las entidades.

Una explicación plausible para los nudos que presenta la actual política pública educativa está en la exacerbación de la mirada econométrica, anclada en el liberalismo y neoliberalismo instalado en la educación superior, lo cual es erigido en dictadura y perdura hasta hoy. Así, la dimensión financiera y el incremento del número de ingresantes han sido los ejes temáticos con mayor realce. Sin embargo, la calidad del currículo y de la docencia quedan invisibilizadas, por lo cual, es factible que se cierre un plantel por problemas de viabilidad financiera. Sin embargo, pareciera que la dimensión pedagógica no tiene la capacidad de imponerse para efectos de consecución de un proceso de enseñanza de calidad.

El ACD realizado permite precisar que los discursos oficiales durante la pandemia hacen pequeñas alusiones a la adaptabilidad educativa, sugiriendo explícitamente el rediseño de las evaluaciones. Sin embargo, se observa que el uso de la palabra adecuación no tiene ninguna relación con el principio de adaptabilidad, por lo cual que no se observan exigencias consistentes desde el nivel central que permitan a los planteles hacer un proceso pedagógico de calidad, con unidades de gestión académica que efectivamente tengan la capacidad de optimizar procesos formativos y no solamente administrar plataformas o sugerir recursos tecnológicos para ser usados en las clases. Es decir, pareciera que la política pública opera con criterios laxos y/o permisivos que no establecen directrices o perfiles docentes que permitan aprendizajes significativos y no solamente el uso de tecnologías educativas.

La laxitud de los textos publicados durante la pandemia, la carencia de exigencias curriculares y pedagógicas hacia las instituciones y la celebración de contratos con empresas tecnológicas son acciones ancladas en una política pública que no posee un diseño que permita superar las inequidades socioeducativas. Así, los hallazgos de este estudio permiten dar cuenta de los elementos ideológicos neoliberales presentes en la política pública que, 
específicamente durante la pandemia, emergen a través de literalidades y omisiones representadas en el corpus de estudio y que remiten, principalmente, a la invisibilización de la calidad de la docencia virtual.

De igual modo, la revisión teórica evidenció la inexistencia de una definición operativa para docencia virtual desde el aparato estatal. Así, al no existir requisitos excluyentes y al estar el sistema colonizado por intereses económicos que obligan al autofinanciamiento de los planteles, entonces, puede acontecer al menos dos escenarios: que la entidad no cuente con profesionales altamente calificados para el desarrollo de actividades docentes; o que teniendo académicos con conocimientos pedagógicos, estos hayan sido adquiridos en la propia entidad, es decir, a través de un proceso formativo endogámico, estando aquello en sintonía con las visiones hegemónicas que, objetivamente, se alinean con la reproducción de estructuras y no con el desarrollo de posibilidades y oportunidades para el estudiantado.

El análisis de los textos permitió reconocer cómo opera la estrategia generalizada de saturación positiva para el concepto de calidad de la docencia virtual, es decir, el modo a través del cual los grupos de poder instalan al mercado como ideología, por lo tanto, se le posiciona como elemento emancipador, concibiendo semánticamente a la educación como un ideal que permite resolver las diferencias económicas, culturales y sociales. Sin embargo, esta concepción neoliberal, que es el sustrato de la mercantilización de la educación, encripta otras problemáticas, como son la supremacía de visión econométrica educativa, por ende, la destinación excesiva de recursos económicos que permitan la existencia de unidades burocráticas administrativo financieras, en desmedro de la destinación de recursos para la docencia e investigación.

En línea con lo anterior, es factible que el uso de plataformas informáticas permita el incremento del número de estudiantes por aula virtual, lo cual, objetivamente deriva en la precarización de la profesión académica, lo cual de algún modo está presente en los textos analizados, los cuales presentan una visión reducida y limitada de la docencia virtual, puesto que todos dichos textos comienzan con lenguajes enunciativos y propuestas curriculares incluyentes, pero rápidamente pasan a defender intereses particulares de multinacionales, resaltando implícitamente la destinación de recursos económicos para la existencia de soportes informáticos y no aludiendo o posicionando como relevante la dimensión pedagógica, puesto que no intentan discursivamente superar las diferencias e inequidades educativas, por ende, el discurso no intenta resolver la insoslayable brecha existente entre lo que dicen las autoridades, lo que hacen los planteles y lo que efectivamente puede ejecutar el docente en el aula.

En alusión a las diferencias entre el discurso oficial y la acción pedagógica en el aula virtual, existe una debilidad de arrastre desde la llegada de la dictadura hasta hoy, y esta radica en que el currículum no se ha constituido en un eje trascendental, tanto para la política pública, como para las instituciones, lo cual devenga en la observación de la OCDE (2017) hacia Chile, la cual señala que la formación superior es altamente segregada y que no reporta las oportunidades laborales deseadas, especialmente, para las personas provenientes de los quintiles más desposeídos.

La disímil calidad formativa en ES, exacerbada en escenarios áulicos virtuales, estaría en contraposición a lo prescrito en los textos legales nacionales e internacionales que hacen 
referencia a dicha calidad educativa como un derecho social exigible, siendo ambos casos causados por políticas públicas laxas y cuyo foco no está en la aceptabilidad y adaptabilidad de la educación en general, y a la dimensión de docencia de calidad en particular. Incluso, antes de la llegada de la pandemia, la OCDE (2017) señaló que la educación superior chilena presentaba bajos niveles de competencias por parte de los graduados según los estándares internacionales; la persistencia de inequidades en el acceso a la educación superior y en el logro de buenos resultados por parte de los segmentos más pobres de la sociedad; alta deserción; multiplicación desarticulada de la oferta de programas; disímil calidad de instituciones y carreras; y escaso desempeño en investigación, según los estándares internacionales.

Es importante destacar que, en el orbe, desde la Declaración Universal de los Derechos Humanos (1948) ha habido preocupación por la calidad de la educación, por lo cual, recibir una instrucción de calidad es un Derecho Humano que debe ser reclamado por las personas y resguardado por los Estados. Por lo mismo, cuando un Estado detenta políticas laxas en materia educativa, entonces, está afectando un derecho fundamental.

Tradicionalmente el concepto de calidad educacional suele ser usado por diferentes grupos e instituciones en diversos sentidos o acepciones. Así, los discursos oficiales de Chile lo han vinculado al financiamiento o acceso de estudiantes vulnerables. Dicho de otra forma, y desde un punto de vista jurídico, el constructo también afecta la exégesis de las normas que regulan la educación superior en Chile, puesto que la imprecisión conceptual puede provocar problemas de interpretación de la ley y, por consiguiente, el cumplimiento de lo mandatado, tanto por los tratados internacionales, como por la normativa nacional, afectando objetivamente a los grupos sociales más pobres, a quienes el Estado no les puede asegurar que la prestación del servicio educativo en el nivel superior universitario cumpla efectivamente con estándares mundiales. Dicho de otro modo, que la formación brindada por los distintos tipos de planteles sea un efectivo factor de acceso a mejores oportunidades laborales y de movilidad social.

El ACD de los textos publicados durante la pandemia permite develar que el principal nudo de las políticas públicas en educación superior en Chile remite al enquistamiento ideológico y predominio de ciertos grupos de poder, los que se encuentran arraigados en el neoliberalismo. Así, el análisis evidencia que, aunque el discurso oficial está tácitamente dirigido a los profesionales que colaboran, ya sea como docentes o directivos en las entidades universitarias y están implicados en el quehacer académico y docente, el verdadero destinatario termina siendo el estudiante, puesto que cada una de las acciones propuestas impactarán en su trayectoria formativa y futuro desempeño profesional.

Se debe destacar que en los documentos analizados no existan citas, referencias y/o argumentos que remitan a sustentos epistemológicos del campo pedagógico-curricular. Es decir, se apela a un discurso eminentemente tecnocrático, propio de otros campos disciplinares, obviando e invisibilizando al discurso pedagógico. En segundo lugar, se observa que los textos intentan persuadir y posicionar una tendencia dominante, esta es la de usar determinadas plataformas informáticas, sin explicitar la justificación de ello desde una perspectiva que remita al quehacer docente y/o avalada por argumentos que permitan asumir la calidad de la docencia desde una visión integrada y que esté alineada con la 
superación de las asimetrías e inequidades educativas existentes en el país. Por el contrario, las estrategias discursivas permiten connotar positivamente el uso de ciertas tecnologías y otorgar un carácter invisible al currículo y al profesorado como garante de la calidad del mismo.

El análisis desarrollado también permitió reconocer cómo los grupos de poder e instituciones ejercen la dominación, es decir, replican y perpetúan estructuras que posibilitan el mantenimiento de desigualdades e injusticias sociales mediante el uso de la comunicación y el lenguaje. Por lo mismo, los textos elucidan el posicionamiento ideológico de las autoridades y que remite a dar preponderancia a los intereses de las empresas prestadoras de servicios informáticos por sobre el quehacer docente y diseño curricular. Dicho de otra forma, cobra relevancia el operador del servicio y no quienes forman y son formados, es decir, docentes y estudiantes. Según esto, el poder y el abuso de poder son producidos y reproducidos en el texto, para lo cual dichos textos utilizaron la saturación positiva y la estrategia de ocultamiento.

Se observa que, en línea con el ACD (van Dijk, 2017; Luna, 2020) existen artificios del lenguaje que permiten imponer modos y prácticas discursivas desde el poder estatal, por lo cual, los textos publicado en pandemia son una instancia de reproducción y universalización de hegemonías, las cuales llegan a las mentes de los sujetos $\mathrm{y}$, aunque existan resistencias, estos discursos persuaden y manipulan a la sociedad, así el cumplir la ley otorga un efecto de verdad y calidad educativa que, en apariencia, marca tendencia. Sin embargo, el fiel cumplimiento de esto no asegura que la docencia virtual entregada sea de calidad pertinente y adaptada a las necesidades del estudiantado.

Tras el análisis de las tres categorías sugeridas por la literatura actualizada alusiva a la calidad de la docencia virtual se puede precisar que existe un pensamiento político e ideológico neoliberal que define las relaciones de poder en distintos escenarios sociales, siendo la educación superior campo y representación de cómo se dan las relaciones dentro de una sociedad injusta y fragmentada, en la cual el poder, la dominación, la manipulación y control del discurso emergen como estrategias de poder de los autores de los textos, es decir, del poder central para constituirlo en discurso dominante. Por ende, a través de las indicaciones dirigidas hacia los aparatos ideológicos del Estado (Althusser, 2005) y que apuntan hacia la tecnologización y virtualización de las aulas, se invisibiliza al currículo y sus diseñadores, a los docentes y sus estrategias pedagógicas en educación superior y al estudiante, lo cual se constituye en el modo a través del cual es factible perpetuar el poder $y$, por medio de prácticas discursivas, generar una validación social de la calidad educativa asociada a el uso de nuevas tecnologías.

El ACD realizado permite precisar que la hipótesis pudo ser probada, es decir, la calidad de la docencia virtual, durante la pandemia, se encuentra invisibilizada por la política pública, siendo el currículo un elemento al cual el discurso oficial alude de manera tangencial, sin establecer marcos teóricos que permitan validar de manera consistente las acciones recomendadas por las agencias estatales. Por otra parte, ello afecta de manera directa a la calidad formativa global, lo cual es una condición de arrastre, es decir, tanto el rol subsidiario del Estado, sustentado en las concepciones neoliberales de la educación y cuyo influjo proviene desde el campo de la economía, como la existencia de agencias estatales con 
miradas tecnocrático-financieras propician la invisibilización de la calidad educativa, en especial de la aceptabilidad y adaptabilidad a las condiciones, circunstancias y tipos de estudiantes.

El uso de las estrategias de saturación positiva y ocultamiento dan cuenta de cómo la política pública intenta invisibilizar el problema de la calidad global de la educación superior chilena, la cual está al debe. Por lo mismo, no se intenta mejorar el sistema, sino más bien, es la propia política pública la que permite la laxitud, para lo cual establece una selección mínima de contenidos, lo cual, objetivamente atenta contra la calidad formativa, en especial en aquellas entidades que, por sus propias autodefiniciones, y porque la ley lo permite, no cuentan con procesos pedagógicos consolidados y evidenciados a través de prácticas, indicadores y resultados asociados a la dimensión curricular, no pudiendo algunas universidades asegurar el aprendizaje de todos los estudiantes, en especial de quienes proviene de segmentos sociales con bajo capital sociocultural.

El discurso oficial a través de silencios y omisiones exacerba las diferencias entre tipos de planteles, mostrando como la política pública educativa nacional instaura, transmite y replica tendencias hegemónicas que, en tiempos de pandemia pareciera ser que buscan la tecnologización de procesos, pero no se aborda el problema de base, este es: qué enseñar, quién debe enseñar y cómo se debe enseñar, por lo cual no se observa la existencia de medidas que efectivamente aseguren la calidad curricular erigida sobre la pertinencia de contenidos, metodologías de trabajo apropiadas y sólida formación del personal académico.

Futuros estudios debiesen ahondar en los discursos oficiales que permitan conocer los perfiles, formaciones y/o competencias que debieran detentar quienes llevan los procesos de aseguramiento de la calidad educativa al interior de las casas de estudio, entre otros aspectos, puesto que, dichos encargados son en definitiva los responsables y/o garantes directos del servicio educativo. Por lo mismo, los planteles debiesen detentar una visión socio jurídica y educativa de dicho trabajo. De lo contrario, burocráticamente la tarea estará realizada, sin embargo, seguirá siendo incompleta, entregando formaciones académicas disímiles y que están muy por debajo de los estándares internacionales establecidos por la OCDE, perpetuando miradas hegemónicas de lo educativo y que han enfatizado en la dimensión financiera de la ES, remitiendo al currículo a un lugar de escasa relevancia

Finalmente, en línea con Espinosa (2015) se puede precisar que aunque las disposiciones de las agencias estatales durante la pandemia remitan a temas educacionales, el propósito real no está en dicho tema, puesto que priman los intereses del mercado, siendo la parte más beneficiada del sistema el oferente y no pudiendo asegurar que los estudiantes provenientes de grupos de menor estatus sociocultural reciban una formación universitaria de calidad, erigida sobre una docencia virtual que conciba a la enseñanza como un proceso de formación entre seres humanos y en la cual, tanto el Estado, como las instituciones puedan asegurar que se está dando una cobertura total de saberes, contenidos y desarrollo de competencias que posibiliten a dichos estudiantes acceder a oportunidades que históricamente les han sido negadas, puesto que, aunque obtengan el anhelado grado universitario, este no les facilitará la movilidad social y tampoco propiciará la superación de asimetrías e injusticias históricas enquistadas y replicadas por un Estado subsidiario. 


\section{REFERENCIAS BIBLIOGRÁFICAS}

Althusser, L. (2005). Ideología y aparatos ideológicos del Estado. Editorial Skla, Bogotá.

Ball, S. J. (2016). Following policy: Networks, network ethnography and education policy mobilities. Journal of Education Policy, 31(5), 549-566. Recuperado de: https://doi.org/10.1080/02680939.2015.1122232

Barberá, E. y Badía, A. (2005). "El uso educativo de las aulas virtuales emergentes en la educación superior". En Revista de Universidad y Sociedad del Conocimiento (RUSC). Disponible en: http://www.uoc.edu/rusc/2/2dt/esp/barbera.pdf $>$ (25/05/09)

Brunner, J. J. (2017). Control de calidad como asunto disputado en la gobernanza de la educación superior chilena. Revista Educación Superior y Sociedad (ESS), 22(22), 43$64 . \quad$ Recuperado http://www.iesalc.unesco.org/ess/index.php/ess3/article/view/32

Buenfil Burgos, R.N. (2009) Análisis crítico del discurso e historia de la educación. En Pini, M. (comp) Discurso y educación. Herramientas para el análisis crítico (pp. 7

Buenfil Burgos, R.N. (2017). Laclau y la educación en América Latina: apropiaciones y debates de un legado. In El legado educativo de los filósofos contemporáneos: De Arendt a Rancière pasando por Badiou, Bauman, Benjamin, Deleuze, Derrida y Laclau (pp. 181-201). Nau Llibres. Recuperado de: https://books.google.es/books?hl=es\&lr=\&id=2qdJDwAAQBAJ\&oi=fnd\&pg=PA181\& ots=1RqBgUEhV0\&sig=sivmjljsTGcNKe1i4yfovY70-vI\#v=onepage \&q\&f=false

Carta de la Organización de los Estados Americanos, 1948. Recuperado de: www.oas.org Chile (2018). Constitución Política de Chile de 1980. Lexis Nexis

Chile (2018). Ley 21091. Ley de Educación Superior (11 de mayo de 2018). Recuperado de: https://www.bcn.cl/leychile/navegar?idNorma=1118991

Chile (2009). Ley 20.370 de 2009. Establece la Ley General de Educación (12 de septiembre de 2009). Recuperado de: https://www.leychile.cl/Navegar?idNorma=1006043

Chile (2006). Ley 20.129 de 2006. Crea el Sistema Nacional de Aseguramiento de la Calidad de la Educación Superior (17 de noviembre de 2006). Recuperado de: https://www.cnachile.cl/SiteAssets/Paginas/Ley\%2020129/LEY-20129_17-NOV2006_\%20ASEGURAMIENTO\%20DE\%20LA\%20CALIDAD\%20(002).pdf

Comisión Nacional de Acreditación. Guía para la autoevaluación interna institucional de universidades (2018).

Comité de Derechos Económicos, Sociales y Culturales (1999b). Observación General número 13. El derecho a la educación (artículo 13 del Pacto). Vigésimo primer período de sesiones.

Gimeno Sacristán, J. (1988) El currículum: una reflexión sobre la práctica. $9^{\circ}$ Ed. Madrid: Ediciones Morata. 
Guzmán, C. (2016). Global trends and their impact on Latin America: the role of the state and the private sector in the provision of higher education. Working Paper $\mathrm{N}^{\circ} 4$. Londres, Reino Unido: Centre for Global Higher Education.

García-Planas, M. I. y Taberna Torres, J. (2020). The transition from the classroom to nonclassroom teaching at the UPC during the COVID-19 pandemic. IJERI: International Journal of Educational Research and Innovation, (15), 177-187. Recuperado de: https://doi.org/10.46661/ijeri.5015

Laclau, E. (2020). Política, hegemonía y populismo: diálogos con Ernesto Laclau. Revista de Estudios Sociales, (71), 101-106. Recuperado de: https://revistas.uniandes.edu.co/doi/abs/10.7440/res71.2020.08

Luna, D. (2020). El dispositivo: una metáfora foucaultiana para la investigación educativa. Athenea Digital. Revista de pensamiento e investigación social, 20(1), 2486. Recuperado de: https://atheneadigital.net/article/view/2486

Marciniak, R. y Sallán, J. G. (2018). Dimensiones de evaluación de calidad de educación virtual: revisión de modelos referentes. RIED. Revista Iberoamericana de Educación a Distancia, 21(1), 217-238. Recuperado de: https://d1wqtxts1xzle7.cloudfront.net/56513336/Dimensiones_de_evaluacion.pdf? $1525770361=$ \&response-content-

disposition=inline\%3B+filename\%3DDimensiones_de_evaluacion_de_calidad_de.pdf \&Expires $=1591809347 \&$ Signature $=$ cECVetUkdor8njuOYpWF05tvf0nVaz3-

47XgsjklKsLTi3pb0UnQwuWrbHtM8GxdLA9eVOvGCDMzbMEIvgU6BLgnzyh2r5kswl ZoSpgp-Hv9sb43NRsSo-

2y9TplnhtQlFjjyILWadGXXhREcqKu3GRPjdZgk3gqud46MJlbr-

laXytWo6oP vAeTKaIGuQODFktXIRtHyshOABkfTEv5zwX5QbqE0rGSlioAlxqxMulsO bCVxViRENSQJuvv7j2QliNxyiWXOAnrtTe9hSNH c4b68MmNCmtBwjxfqYtRTOneZB ZG4TKR1perUwiXhr3cwT86hsCCB7b0 06-d8Kw_\&Key-PairId=APKAJLOHF5GGSLRBV4ZA

Martelo, R. J., Franco, D. A. y Oyola, P. S (2020). Factores que influyen en la calidad de la educación virtual. Revista Espacios 41(6), 352-361. Recuperado de: https://www.revistaespacios.com/a20v41n46/a20v41n46p29.pdf

Morelli, S. (2017). El currículum universitario y la relación con el saber. Nociones desde la posmodernidad. Investigación cualitativa, 2(2), 68-82.

Naciones Unidas. Observación General $\mathrm{N}^{\circ} 13 . \quad$ Recuperado de: http://tbinternet.ohchr.org/_layouts/treatybodyexternal/Download.aspx?symbolno $=\mathrm{E} \% 2 \mathrm{fC} .12 \% 2 \mathrm{f} 1999 \% 2 \mathrm{f} 10$ \&Lang=

OCDE (2017). Education in Chile, Reviews of National Policies for Education. OCDE Publishing.

Protocolo de San Salvador. Protocolo Adicional a la Convención Americana Sobre Derechos Humanos en materia de Derechos Económicos, Sociales y Culturales, "Protocolo de San Salvador" (adoptado en San Salvador, El Salvador, el 17 de noviembre de 1988, en 
el decimoctavo período ordinario de sesiones de la Asamblea General). Recuperado de: http://www.oas.org/juridico/spanish/tratados/a-52.html

Rama, C. (2012). La reforma de la virtualización de la universidad. Universidad de Guadalajara, Sistema de Universidad Virtual. Recuperado de: https://www.recursos.portaleducoas.org/sites/default/files/154.pdf

Rama, C. (2016). El aseguramiento de la calidad de la educación virtual. Universidad Católica Los Ángeles de Chimbote. Recuperado de: http://utex.uladech.edu.pe/handle/ULADECH_CATOLICA/16

Salazar, J. M. y P.S. Leihy. (2017). El largo viaje: los esquemas de coordinación de la educación superior chilena en perspectiva. Archivos Analíticos de Política Educativa 25.4, 1-29.

Superintendencia de Educación Superior de Chile. (2021). Informe Consolidado de Respuestas a las Observaciones Del Período de Información Pública de la Norma de Carácter General N ${ }^{\circ} 1$ Sobre Obligación de Informar de las Instituciones de Educación Superior. Recuperado de: https://sesuperior.cl/wpcontent/uploads/2021/01/NCG1_consolidado-respuestas-a-observaciones.pdf

Torrecillas, C. (2020). El reto de la docencia online para las universidades públicas españolas ante la pandemia del Covid - 19. ICEI Papers COVID - 19, (16). Recuperado de: https://eprints.ucm.es/60050/

Van Dijk, T. A. (1998). Ideología: Una aproximación multidisciplinaria. Barcelona: Gedisa. Van Dijk, T. (2016). Discurso y conocimiento: Una aproximación sociocognitiva (Vol. 302632). Editorial Gedisa.

Van-Dijk, T. A. (2017). Análisis crítico del discurso. Revista Austral de Ciencias Sociales, (30), 203-222. Recuperado de: http://revistas.uach.cl/index.php/racs/article/view/871

Verger, A. y Parcerisa, L. (2017). La globalización de la rendición de cuentas en el ámbito educativo: una revisión de factores y actores de difusión de políticas. Revista Brasileira de Política e Administração da Educação-Periódico científico editado pela ANPAE, 33(3), 663-684. Recuperado de: https://www.seer.ufrgs.br/rbpae/article/view/79301

Verger, A. y Normand, R. (2015). Nueva gestión pública y educación: Elementos teóricos y conceptuales para el estudio de un modelo de reforma educativa global. Educação \& Sociedade, 36(132), 599-622. Recuperado de: https://dx.doi.org/10.1590/ES010173302015152799

Zapata, G. y Tejeda, I. (2017). Higher education systems and institutions, Chile. En P. Texeira, \& J-Ch.Shin (Eds.), Encyclopedia of International Higher Education Systems and Institutions (pp.1-14). Nueva York, Estados Unidos: Springer. 